\title{
Cultura Organizacional em Ambiente Burocrático
}

\author{
Luiz Alex Silva Saraiva
}

\section{Resumo}

O objetivo desse artigo é descortinar as manifestações da cultura organizacional em uma organização de caráter público, tendo a questão do foco no cidadão um papel preponderante na análise, para isso particularmente destacando as relações existentes entre a cultura da organização e as normas burocráticas. Mediante uma estratégia de pesquisa qualitativa, foram realizadas trinta entrevistas em profundidade com funcionários de uma universidade pública para identificar os principais aspectos do trabalho. Os resultados encontrados revelam que a lógica burocrática é responsável por uma dinâmica complexa entre os funcionários e a organização, com reflexos perceptíveis sobre a cultura da organização, que apresenta significativa influência das normas internas.

Palavras-chaves: cultura organizacional; burocracia; cidadão; nova administração pública.

\begin{abstract}
Dealing to discover the manifestations of organizational culture in a public organization, the paper has the intention, having the focus on citizen a main role in the analysis. It is emphasized particularly the existing relations between culture of organization and bureaucratic rules. By a qualitative approach, thirty interviews in depth were realized with employees of a public university to identify the main aspects of this work. The results show that the bureaucratic logic is responsible for a complex dynamics between the employees and the organization, with perceivable consequences on its organizational culture, that presents strong influence of the internal norms.
\end{abstract}

Key words: organizational culture; bureaucracy; citizen; new public administration. 


\section{Considerações Iniciais}

A cultura organizacional tem sido colocada por diversos estudiosos como importante aspecto da análise organizacional, capaz de oferecer parâmetros úteis para uma compreensão ampliada do comportamento da organização. A construção de análises baseadas em tal perspectiva possibilita uma visão diversa do que normalmente tem sido feito na administração, pois considera a influência de elementos não objetivos, que têm sua influência ofuscada pelo pragmatismo predominante na literatura da área.

O entendimento de tais pontos reveste-se de importância singular, associada à necessidade de repensar a esfera organizacional e discutir a respeito de como a nova realidade impõe às organizações um processo de realinhamento de variáveis rumo a uma maior integração dos ambientes interno e externo. Partindo de enfoque voltado aos aspectos culturais e suas diversas subdimensões e manifestações, este trabalho busca traçar um parâmetro entre o ambiente burocrático de uma organização pública e a cultura organizacional, tendo a questão do foco no cidadão um papel preponderante na análise.

Para atender a este propósito, esse artigo se encontra organizado em quatro grandes blocos. O primeiro, o suporte teórico, destaca inicialmente a burocracia e sua perspectiva no âmbito publico, a administração pública e o foco no cidadão e a multidimensionalidade da cultura organizacional. Na segunda parte, são destacados os procedimentos metodológicos utilizados para a confecção do estudo. A análise e a discussão dos dados são tratadas na terceira parte. Por fim, são apresentadas as principais conclusões a respeito do tema ${ }^{(1)}$.

\section{Suporte Teórico}

\section{As Facetas da Burocracia no Setor Público}

Inicialmente sistematizada por Weber enquanto forma de dominação, a burocracia se sustenta sobre o conhecimento técnico, que além de lhe conferir caráter racional, a transforma em instrumento capaz de assegurar alta eficiência administrativa. Isso pressupõe certa racionalidade impessoal que, guiada por regras formais que padronizam e conferem igualdade no tratamento dos casos, define 
com precisão as relações de mando e subordinação, mediante a distribuição das atividades a serem executadas tendo em vista os fins a que se visa.

A impessoalidade das normas, todavia, em geral termina por transformar um padrão descritivo de critérios e relações em padrão prescritivo, sem espaço para a informalidade e o desenvolvimento de noções mais flexíveis de gerenciamento, desconsiderando o elemento humano na organização. Merton (1966), em um estudo clássico, denominou esse fenômeno de incapacidade treinada, uma situação em que a preparação dos funcionários pode tornar-se inadequada em contexto dinâmico. Assim, em última instância, a rigidez burocrática produziria desajustes, fontes de conflitos potenciais entre o público e o funcionário, já que os objetivos formais se tornariam dogmas imutáveis, pois derivam da norma burocrática, e esta enrijece qualquer tentativa de reformulação (Carbone, 1995).

Diante da ausência de uma dinâmica intra-organizacional inerte, os membros da organização ficam à mercê da norma, tendendo a um processo de acomodação de interesses. Como conseqüência surgem os sentimentos de desestímulo, de estabilidade e de resistência a mudanças, que, aliados à isonomia salarial e à falta de preocupação com os resultados, são algumas das características que permeiam a maior parte das organizações, em particular as organizações públicas (Medici e Silva, 1993; Carbone, 1995).

A administração pública, de acordo com Castor (1987), reage de forma lenta e insatisfatória às mudanças econômicas e sociais que se processam à sua volta, tornando mais agudas e sensíveis suas distorções e deficiências. Kliksberg (1994) compartilha desse ponto de vista, ao afirmar que a administração burocrática no serviço público, embora tenha sido criada para esse fim, não garante nem rapidez, nem boa qualidade, nem custo baixo para os serviços prestados ao público, sendo na verdade lenta, cara, auto-referida, e pouco ou nada orientada para o atendimento das demandas dos cidadãos.

Para atender a estas demandas, Bresser Pereira $(1996,1997)$ sustenta que o novo papel do Estado é o de facilitar a competitividade internacional, o que pode ser conseguido mediante melhoria dos seus sistemas de gestão para uma ação mais efetiva e eficiente em benefício da sociedade. O Estado é gradativamente levado a enfatizar tanto o atendimento das necessidades de regulação quanto a prestação dos serviços aos seus clientes/cidadãos, por meio de incentivos a programas de flexibilização da gestão pública, tornando sua máquina administrativa mais barata, ágil e receptiva à inovação gerencial e à autonomia administrativa (Silva, 1994). 


\section{A Administração Pública e o Foco no Cidadão}

A nova administração pública procura identificar o cidadão, prestar-lhe contas; em resumo, ajustar-se às suas reais necessidades (Kliksberg, 1994). Como estratégia, usa a descentralização e o incentivo à criatividade e à inovação e envolve ainda uma mudança na estratégia de gerência que, entretanto, tem de ser posta em ação em uma estrutura administrativa reformada, cuja ênfase seja a descentralização e a delegação de autoridade (Bresser Pereira, 1997).

A diretriz mestra da nova administração pública é desenvolver nos funcionários um compromisso com a construção de uma sociedade mais preparada para enfrentar as novas demandas contextualizadas em uma era de mudanças. A grande tarefa a ser realizada compreende, entre outros aspectos, a revisão dos serviços de atendimento ao público com vistas a sua maior eficiência e humanização. Isto implica repensar profundamente os modelos organizacionais vigentes (Kliksberg, 1992).

A evolução das necessidades do setor público conduz a uma nova direção, no sentido de considerar o atendimento ao cidadão como aspecto positivo e, como tal, acima das tentativas de restringir decisões e atitudes tomadas a seu favor. Concentrar o foco de uma organização no cidadão não é apenas questão de proclamar uma nova política; é processo que envolve estratégias, sistemas, prioridades, atitudes e comportamentos, em suma, trata-se da cultura da organização (Cannie, 1994; Freemantle, 1994; Gracioso, 1995).

A identificação das limitações nas atividades desempenhadas por organizações públicas - e da sua necessidade de redirecionamento - não encontra correspondente à altura na mobilização de práticas organizacionais rumo à melhoria dos padrões vigentes. Assim, a compreensão de como os fenômenos organizacionais são afetados e influenciam o ambiente externo é fundamental para a adaptação das organizações públicas a novos padrões; daí o estudo da cultura da organização como instrumento de percepção e captação dos matizes existentes e de como estes se relacionam com as potencialidades organizacionais.

\section{A Cultura Organizacional e suas Multidimensões}

A cultura organizacional, embora seja um dos temas mais estudados na teoria das organizações, apresenta-se com uma simplicidade aparente, que reveste e oculta um fenômeno cuja complexidade elude e confunde a maioria dos pesquisadores (Fleury, 1990). A popularização desse conceito, de acordo com Barbosa (1996), deve-se à sua possibilidade de instrumentalização, uma vez que é funda- 
mental dimensionar as relações entre os aspectos objetivos e representacionistas da administração, e esperar que esse novo paradigma produza novos e melhores instrumentos de intervenção e compreensão da realidade; mas deve-se ter em mente que, embora a cultura influencie alguns aspectos, não determina tudo, pois há outros fatores concomitantes e influenciadores das diversas facetas organizacionais (Aktouf, 1993; Hickson e Pugh, 1995).

Além disso, o conceito de cultural abre o caminho para uma discussão mais profunda, que é o peso da dimensão simbólica nas organizações e nas diferentes formas de gestão (Barbosa, 1996). Dessa forma, a cultura assume papel de destaque no comportamento das organizações, à medida que influi no modo de vida, nos padrões e nos valores das pessoas que, durante a maior parte do tempo, se dedicam às organizações, para onde transportam não apenas seus conhecimentos técnicos, como também todas as características de suas personalidades (Santos, 1990).

A cultura organizacional pode ser encarada também como universo cultural formado pelos pressupostos, crenças e valores compartilhados pelos membros de uma organização, sendo derivada de um ambiente social específico (Hofstede, 1991). Em outras palavras, a cultura é apreendida e aprendida mediante processos de socialização, o que se verifica tanto no nível social quanto no nível organizacional.

Sendo fenômeno grupal, resultante e característico de uma coletividade, é um conceito que engloba tanto fatos materiais como abstratos, resultantes do convívio humano institucional, expressando significados subjetivos, constituídos, mantidos e modificados por atores sociais e também como estrutura, à medida que objetiva atividades e práticas sociais (Rodrigues, 1991; Santos, 1994). Cada organização, portanto, possui uma cultura organizacional particular, sustentada, transmitida e transformada por meio da interação social dos mais diversos agentes.

A cultura de uma organização sofre grande influência de seus fundadores e líderes, dos seus momentos críticos, do seu mercado etc. A partir da sua fundação, as organizações consolidam e perpetuam um padrão comportamental único, resultado das variáveis circunstanciais de sua história (Freitas, 1991; Freitas, 1997); contudo tal padrão não permanece estático; pelo contrário, está em contínua transformação. A mudança pode ocorrer por pressões externas à organização, ou por alterações internas.

Mudanças nos padrões culturais de uma organização, como parece atualmente ser o desejo de estratos significativos da sociedade com relação à atuação das organizações públicas, podem ser provocadas com o objetivo de amenizar carac- 
terísticas indesejáveis. As tentativas de mudança, porém, podem encontrar obstáculos bastante significativos para se consolidarem, sendo assim necessário agir diretamente sobre os pressupostos básicos da organização e suas relações de poder, o que evidentemente provoca resistências muito fortes (Fleury, 1988; Aktouf, 1993).

A cultura organizacional funciona ainda como sistema de controle social, pois freqüentemente se sente que dispõe de grande autonomia, mesmo quando, paradoxalmente, a conformidade é muito maior (O’Reilly, 1989). Em alguns casos, pode ser entendida como sofisticada técnica de controle gerencial, que encoraja a identificação psicológica e emocional dos empregados com a organização (Rodrigues e Collinson, 1995). Nesse sentido, funciona informalmente, aprovando ou proibindo comportamentos, dando significado, direção e mobilização para os membros da organização. O controle se materializa por normas por meio das quais seus membros seguem um comportamento esperado, aceito ou apoiado pelo grupo. Não obstante sua sutileza, os padrões de conduta não escritos permeiam o estilo das relações intra-organizacionais, recompensando e incentivando, ou punindo e colocando no ostracismo aqueles que os violam (Freitas, 1991; Santos, 1994).

Embora seja constituída por uma série de padrões não escritos, a cultura organizacional na esfera pública possui peculiaridades promissoras de análise, devido ao fato de esta ser organizada mediante um conjunto de regras de caráter impessoal - como em toda burocracia - que, de certa forma, delimita formalmente o espaço organizacional. Assim, sua observação permite a análise desta complexa relação entre o aspecto normativo e o elemento cultural, que pode ser ligado ou antagônico à idéia de padrão ideal de comportamento. A cultura organizacional burocrática caracteriza-se por ser um tipo de cultura hierarquizada, onde existem linhas claras de responsabilidade e autoridade, sendo que o trabalho é organizado e sistemático. As organizações que possuem esse tipo de cultura normalmente são estáveis, cuidadosas e maduras (Wallasch apud Santos, 1990).

Dentro do universo de organizações burocráticas, a universidade em si possui uma problemática complexa em termos organizacionais, pois ora é tratada como tipo especial de burocracia, ora como tipo similar às demais organizações burocráticas. A sua complexidade reflete-se na multiplicidade de parâmetros internos, o que confere ao critério político a tarefa de conseguir o consenso para o alcance dos objetivos da organização. As dimensões de uma organização burocrática são também entendidas como expressões de poder e ideologias, à medida que os modos de organização e de operacionalização servem de instrumentos para os grupos obterem o poder e nele se manterem. Se, por um lado, funciona como centro de pesquisa, dispondo para isso de recursos específicos, instalações, 
material, equipamentos e mão-de-obra especializada etc., por outro a universidade possui o papel de ser um centro disseminador de conhecimento, atuando fortemente na área de ensino em nível de graduação e de pós-graduação. Ao mesmo tempo, possui uma faceta social, ligada aos projetos desenvolvidos junto à comunidade na qual está inserta, o que põe naturalmente em destaque a observação da burocracia existente em uma organização com esse tipo de complexidade. Todas essas variáveis são permeadas pela questão política, provavelmente com uma intensidade não encontrada em nenhum outro tipo de organização.

\section{Procedimentos Metodológicos}

Em função da multidimensionalidade do fenômeno em estudo, técnicas isoladas pouco contribuem para sua apreensão e compreensão. Com o intuito de investigar o assunto em profundidade, optou-se pela técnica do estudo de caso. É preciso ressaltar, entretanto, que esta não é uma escolha metodológica, mas uma escolha do objeto a ser estudado (Stake, 1994). A unidade de análise utilizada pode ser caracterizada como organizacional, a fim de verificar como as disposições burocráticas contribuem para a composição da cultura da organização analisada.

Composta por trinta funcionários públicos de uma instituição pública de ensino superior, a amostra da pesquisa, embora não possua ampla representatividade em termos estatísticos, atende, de forma adequada, aos objetivos desse estudo. A técnica de amostragem utilizada foi do tipo não-probabilística intencional, técnica usada quando uma amostra de áreas é escolhida propositadamente, porque tem certas características típicas para a observação do fenômeno. O fator intencionalidade da amostragem foi definido pela opção em efetuar uma análise em diversas unidades de ensino superior, responsáveis pela emissão de documentação de alunos de graduação e de pós-graduação. Há nestas unidades condições adequadas para a análise dos fenômenos estudados, já que se verifica um embate do ponto de vista cultural, pois há tanto um estreito contato com o cidadão (com suas demandas específicas), quanto a necessidade de cumprimento de padrões de organização e controle internos - a ênfase em procedimentos burocráticos. É válido aqui ressaltar que esse estudo não permite generalizações de qualquer natureza, sendo suas conclusões válidas apenas para as unidades pesquisadas. As expressões serviço público, esfera pública, organizações públicas, entre outras, são utilizadas como recurso semântico, para evitar a repetição demasiada da expressão órgãos responsáveis pela emissão de documentação, contudo sem o intuito de promover generalizações. 
A coleta de dados foi efetuada mediante um roteiro de entrevista semiestruturado composto de questões abertas, que antes de tentar apenas propor ao entrevistado padrões uniformes de resposta, visam a captar pressupostos, crenças e valores compartilhados pelos membros de uma organização. Inserido em uma estratégia qualitativa, o material coletado recebeu um tratamento de forma tal, que identificasse os traços organizacionais reveladores da cultura vigente na organização; portanto a organização, análise e interpretação dos dados buscaram elementos para a compreensão dos principais traços da cultura de uma organização burocrática.

Vários critérios podem ser empregados para o alcance da validade de um estudo, de forma que a seleção da organização levou em consideração um elenco de restrições consideradas essenciais à sua validação científica. Sua adoção permitiu o delineamento de um perfil organizacional adequado à consecução dos objetivos desse estudo. Os critérios adotados foram os seguintes:

. a organização deveria pertencer ao setor público, por este estar sendo pressionado a efetuar modificações na sua forma de atuação e possuir uma sólida tradição na sua área de atuação, a fim de se observarem padrões culturais consistentes;

- a organização deveria ser regida por normas de caráter burocrático com o intuito de se verificar sua inter-relação com a questão da cultura organizacional;

- a organização deveria responder a demandas específicas por parte de seus cidadãos, de maneira a avaliar até que ponto tais demandas são satisfeitas, levando em consideração as limitações da própria burocracia.

Além dos critérios acima expostos, destaca-se como característica peculiarmente interessante para a análise o fato de a organização estudada ser uma das mais importantes universidades do país, possuindo um grau de complexidade e inter-relações internas e externas consideráveis e, por isso, naturalmente interessantes como foco de análise.

\section{O Caso em Estudo}

A organização pesquisada foi fundada como instituição estadual de ensino superior em 7 de setembro de 1927, sendo resultado da fusão de cinco centros de ensino (Direito, Odontologia, Farmácia, Medicina e Engenharia). Federalizada em 1949, quando já abrigava a Escola de Arquitetura e as Faculdades de Filosofia e de Ciências Econômicas, a Universidade Federal de Minas Gerais (UFMG) 
atualmente encontra-se estruturada em dezenove unidades de ensino superior, nas quais estão alocados 2.400 professores e 4.500 funcionários técnico-administrativos, que atendem a 22.000 alunos de graduação e pós-graduação, além de 19.000 em cursos de extensão.

O fato de ter surgido da fusão de centros de ensino e de ter-se desenvolvido por meio da criação de escolas e faculdades nas mais diversas áreas de ensino, fez com que os processos administrativos fossem duplicados em várias instâncias. Isso gerou, em particular, a multiplicação de órgãos responsáveis pela emissão de documentação em todas as unidades, o que interessa diretamente a esse estudo, pois nessas unidades há confrontos entre a cultura estabelecida pelas disposições burocráticas e a cultura que se quer implantar na nova administração pública, de ênfase às demandas diferenciadas dos cidadãos.

\section{Análise das Entrevistas}

As entrevistas realizadas buscaram subsidiar uma análise mais aprofundada das relações dos funcionários públicos com uma organização regida pela burocracia. Com esse intuito, trabalhou-se com algumas variáveis, agrupadas em blocos temáticos, para, em última instância, identificar o que se poderia denominar de traços gerais de uma cultura organizacional em ambiente burocrático. Trabalhou-se com sete grandes blocos, que tratam de alguns dos pontos mais significativos das entrevistas, apresentados a seguir.

\section{Burocracia e Serviço Público}

Para a compreensão de como se manifesta a cultura em uma organização burocrática, faz-se necessário explorar a noção que os próprios funcionários possuem a respeito do que é a burocracia e de como o serviço público é por eles percebido. Uma visão disseminada entre os funcionários é a de que houve poucos avanços no que concerne à gestão.

“A norma, dentro do serviço público, ainda é o papel e o carimbo. Muitas vezes vemos uma ênfase na burocratização em detrimento de uma busca pela maior eficiência. O serviço público ainda é muito burocrático" (relato).

Tal visão, de natureza negativa a respeito da própria natureza da organização à qual dedicam a maior parte do tempo, é complementada por outros pontos de 
vista a respeito da maneira pela qual o trabalho é organizado, e a monotonia daí decorrente.

"O servidor público, após anos de trabalho, vai ficando muito bitolado, sem motivação, sem perspectiva. A pessoa perde a vontade de trabalhar, é levada a tomar uma atitude passiva diante do seu trabalho. Chega ao ponto de nem quererem mais ir ao trabalho, tamanha a falta de estímulo” (relato).

A monotonia não é exclusividade das organizações públicas, de certo; os moldes pelos quais está organizada boa parte dos processos de trabalho, principalmente em um país como o Brasil, deixam muito a desejar em matéria de inovação e criação de ambientes propícios ao desenvolvimento de novas habilidades e exploração de formas alternativas de produtividade: em geral opta-se por uma organização com traços mecanicistas, porque é o que vem tradicionalmente sendo feito ao longo do tempo, sem grandes pressões por modificações mais efetivas. No setor público, entretanto, há maiores reflexos no tocante à cultura, pois parece haver, mais do que nas organizações privadas, um nível de apego à forma tradicional pela qual as atividades se encontram organizadas, com efeitos indesejados sobre as iniciativas de inovação.

\section{Inovação Organizacional}

A situação, contudo, tende a adquirir novos contornos. Foram manifestadas algumas reações de apoio a inovações na gestão, destacando-se a importância de modernização das formas de gestão vigentes, a fim de assegurar a sobrevivência das organizações públicas no futuro.

"É bom sempre inovar, porque tem que haver certa regularidade nos seus processos, mas não [sem] um pouco de inovação. Inovação é sempre desejável, é necessário sempre inovar” (relato).

Contudo há a percepção de que mudar não é um processo fácil. Destaca-se como obstáculo no setor público a tradição do sistema, que age enquadrando as não-conformidades e limitando o potencial de modificação embutido em novas idéias.

"A pessoa tem que se enquadrar com essas novas idéias. Se não chocou com o sistema, até aceitam. Agora, se se opor, tem que rever as suas idéias. Infelizmente tem um sistema implantado que não muda de jeito nenhum. Assim, ou você se enquadra no sistema atual, ou você entra com várias idéias e depois acabam morrendo. As novas idéias são, na 
maioria das vezes, podadas. É impossível sugerir novas soluções. A situação chega a ser caótica; todos mecanizados, robotizados” (relato).

Os entrevistados enfatizam que a postura da mudança pela mudança - sem parâmetros bem definidos a respeito do que é flexibilidade - ao contrário de flexibilizar, pode fazer ruir todo o sistema, porque, de um lado, podem estar sendo propostas soluções mais desastrosas do que os problemas para os quais foram demandadas; por outro, há que se considerar a relação do próprio funcionário com o novo, não estabelecida nos manuais internos. Tais colocações parecem indicar uma necessidade de maior cautela com relação a planos de modernização de rápida implementação e com ampla abrangência, muitas vezes modificando práticas que não carecem de alterações por apresentarem resultados efetivos.

"A inovação deve ser procurada de acordo com a necessidade, porque muitos servidores não sabem lidar com o novo. Nem tudo que é novo é bom, e nem tudo que é velho é descartável. Muitas pessoas inventam certas soluções que são muito piores do que os problemas que as estimularam. Você deve inovar no lugar que precisa” (relato).

Observa-se uma lógica de preservação muito peculiar: de um lado, encontramse as normas burocráticas, fonte de enrijecimento dos procedimentos nas organizações públicas; de outro, a ausência de tais regulamentos significa, contraditoriamente, uma ameaça a funcionários que foram talhados e disciplinados a seguir uma racionalidade preestabelecida nos manuais. Ainda se pode inferir do ponto de vista dos entrevistados uma relação entre estabilidade, regularidade e função social da organização pública versus flexibilidade, inconstância e atendimento sob medida das necessidades dos cidadãos, o que caracterizaria uma lógica mais próxima do mercado, como será tratado a seguir.

\section{Papel Social da Organização Pública}

Fundamental aos funcionários entrevistados é o caráter social das organizações públicas, porque isso é o que basicamente as diferencia das organizações de caráter privado. Há uma percepção de que a auto-referência é uma característica que precisa ser evitada a todo o custo, por meio de maior proximidade do mercado; mas a perspectiva social precisa prevalecer sobre a ótica de mercado.

"As atividades públicas deveriam ter uma orientação maior para o mercado, uma ênfase mais forte na procura, mas sem jamais perder o seu caráter social” (relato).

Por um lado, os entrevistados defendem que não é apenas o lucro que deve 
impor a forma de organização das atividades da organização pública. Por outro, colocam que, em face de contexto mais dinâmico, falta aos funcionários maior qualificação para enfrentar os novos desafios.

"As finalidades das empresas privadas são fundamentalmente diferentes daquelas nas organizações públicas. Enquanto essas visam o benefício e o bem-estar social, aquelas objetivam basicamente o lucro, o retorno financeiro. Acho que falta à universidade pública e, de uma maneira geral, ao setor público, maior qualificação administrativa associada à visão de mercado" (relato).

Outro aspecto ressaltado é que o papel social das organizações públicas, nas quais a universidade se inclui, deve passar também pela transparência de informações à sociedade, à qual tais organizações devem servir. A permeabilidade da universidade, enquanto organização criada para o atendimento da população em geral, aparece nas opiniões e demandas dos seus cidadãos e foi especificamente colocada pelos entrevistados.

"Nem sempre a sociedade fica sabendo o que está acontecendo. Se fosse mais rígida [sua monitoração], eu acho que não estaria tão mal quanto está. A educação não estaria tão mal, a saúde também não estaria tão mal. Você vai cobrando as coisas na medida em que você convive” (relato).

A cultura organizacional, dessa forma, é um quadro complexo de visões a respeito do que a organização pública é e do que deveria ser. Tendo a universidade em si uma natureza complexa, é de certa forma previsível que, na priorização de objetivos, haja a possibilidade de conflito entre os preceitos solidificados por uma burocratização organizacional e a lógica de mercado.

\section{Cumprimento de Normas versus Flexibilidade Funcional}

Muito do que se discute em termos de modernização organizacional no setor público passa pela questão do cumprimento de normas. Até que ponto o cumprimento sistemático de normas enrijece os procedimentos e dificulta um atendimento mais personalizado do cidadão? As respostas encontradas parecem apontar no sentido de que ainda há um sentimento de dependência das normas e regulamentos internos como único meio possível de continuar a proporcionar estabilidade (e direcionamento) à estrutura vigente.

"Normas são feitas para ser cumpridas, porque se for desobedecer, isso aqui vira uma bagunça. Pra funcionar, eu acho que, infelizmente, precisa ter regras e normas. Porque tem que ter um controle do seu trabalho. Aqui tudo é 
muito grande; se um começa a fazer uma adaptação, o outro lá na frente adapta do jeito dele; o outro adapta do jeito dele, todo mundo adapta e não chega a lugar nenhum; aí você acaba fazendo uma bagunça” (relato).

Contudo essa não é uma visão compartilhada por todos os entrevistados. Percebe-se certa limitação inerente às normas e um senso crítico com relação às suas finalidades se faz presente. Um dado que aflorou nas entrevistas é a preocupação, por parte de alguns funcionários, em não se deixar limitar pelo disposto em manuais e regulamentos internos, trabalhando em prol da satisfação das necessidades do cidadão e da eficiência administrativa.

“Às vezes é até preciso desobedecer alguma coisa; não significa que desobedecer está prejudicando, porque eu acho que você tem que se adaptar [às demandas específicas dos cidadãos]” (relato).

"Nós temos as normas que nós temos que seguir, mas se tem alguma pessoa que precisa de um documento urgente, eu facilito, é óbvio. Você tem que obedecer, mas você não está infringindo nada” (relato).

É interessante notar que alguns funcionários usam como justificativa para o cumprimento sistemático das normas internas o não-favorecimento que a flexibilização das normas poderia suscitar. Tal preocupação é interessante, porque traz à tona a questão dos critérios políticos em um ambiente profissional de trabalho, problema que foi uma das motivações weberianas para a sistematização da teoria da burocracia, uma vez que a impessoalidade, de acordo com seu ponto de vista, é que dava a base de sustentação para a meritocracia.

"Você tem que adaptar o regulamento. Você tem uma regra no seu trabalho. Você tem que trabalhar obedecendo àquilo. Se você vai contra essa regra, você começa a abrir uma exceção no seu trabalho. É meio complicado. Deve-se buscar a satisfação [do cidadão] desde que não privilegie um e outro seja prejudicado, porque antes você não abriu exceção” (relato).

Os métodos tradicionais para a resolução de problemas administrativos, incluindo os manuais, são alvo de críticas por parte dos entrevistados, porque, embora sua utilização seja considerada prática, não se pode valer apenas de suas disposições para o dia-a-dia na organização.

"As pessoas às vezes criam normas, escrevem manuais, mas esquecem de revisá-los” (relato).

Aparentemente, a noção vigente é a de que os regulamentos são imperfeitos, porque cobrem exaustivamente procedimentos que poderiam ser melhorados, 
com ganhos de eficiência para o sistema; mas a flexibilidade, à medida que deve ser aplicada, é um critério de natureza tão subjetiva, que é melhor ater-se ao disposto nos manuais de organização internos.

"Se você acha que uma coisa pode funcionar, se você acha que é melhor do que a forma que estava sendo feita, então... É melhor confiar em métodos já comprovados, mas sem abrir mão do novo” (relato).

A nova administração pública postula que a ênfase no cidadão, consumidor final dos seus serviços, deve prevalecer, a fim de que o Estado seja mais bem direcionado no atendimento de suas demandas específicas.

"Na teoria, o Estado deveria direcionar todas as suas atividades para beneficiar o consumidor final; mas na prática isso não acontece. As pessoas se concentram demais na papelada. Eu acho que o Estado não está nem aí para o consumidor final” (relato).

Em linhas gerais, parece haver consenso a respeito de que a flexibilização dos procedimentos administrativos, ao contrário do que está sendo requerido pela sociedade, na realidade tem-se constituído mais uma retórica de modernização do que um conjunto de práticas e melhorias efetivas rumo à satisfação das demandas dos cidadãos. Um dos argumentos mais freqüentemente utilizados para sustentar tal ponto de vista é a depredação da imagem do funcionário público.

\section{Valorização do Funcionário Público}

Outro bloco do roteiro de entrevistas se concentrou especificamente em levantar a percepção do servidor público sobre si mesmo e até que ponto tal imagem contribui para a cultura de uma organização burocrática. As respostas destacam as limitadas perspectivas de progressão funcional, a desvalorização da figura do servidor público no contexto atual e o processo de desmotivação decorrente.

"Deve haver uma perspectiva de crescimento e valorização dentro do funcionalismo; a estagnação leva a um forte desestímulo do servidor. Promoções e treinamento são importantes para o progresso e renovação do atendimento" (relato).

"Nenhum funcionário público tem valor nem para o governo, nem para o próprio público. Não se dá o devido valor ao funcionário. Ele é visto de uma forma totalmente distorcida pela sociedade” (relato).

No entanto é discordância geral que o fato de não terem o seu valor reconhecido pelo governo e pela sociedade deve ter correspondente no descompromisso 
com o desempenho no trabalho. Nesse sentido, os entrevistados parecem ter em mente o papel que têm de desempenhar a fim de que as organizações públicas como um todo respondam, de maneira adequada, aos anseios da população.

“Não é porque eu ganho pouco que eu vou prejudicar o cidadão. A maioria [dos funcionários públicos] passa uma imagem de pessoas que não querem trabalhar, que tratam mal, e isso passa para todos” (relato).

Quando tocada especificamente a questão do atendimento, fica claro para os entrevistados qual o seu papel em face do cidadão e qual o tipo de atendimento que ele merece.

"O funcionário da universidade, e não somente dela, mas também de todas as organizações públicas, trabalha com um público de todos os segmentos sociais, econômicos ou profissionais, e deve estar preparado para prestar um bom atendimento a esse público. É importante que o funcionário público evite um atendimento ao público como aquele que, infelizmente, estamos acostumados a receber: viciado, obtuso, desrespeitoso e preconceituoso" (relato).

A imagem que os funcionários entrevistados possuem a respeito de si mesmos não condiz com o veiculado maciçamente na mídia nos últimos anos. Eles se vêem, apesar de todos os problemas identificados, como necessários à manutenção de um serviço público voltado às necessidades da população, precisando, para isso, de uma espécie de contrapartida, um processo de valorização funcional, a fim de que possam recuperar, ainda que só em parte, a motivação perdida em anos de questionamento sistemático do seu papel e utilidade. Tal valorização passa não apenas por incentivos financeiros, mas também (e talvez principalmente por) incentivos simbólicos, ferramentas úteis na restauração da auto-imagem funcional.

\section{Controle Organizacional}

A restauração da imagem dos funcionários não pode ser um empreendimento isolado; precisa ser acompanhada de outras iniciativas para modificar efetivamente o quadro que se apresenta. Um dos mais importantes trabalhos a ser realizado nesse sentido é redimensionar o uso de controles no serviço público. Os entrevistados tendem a concordar, destacando que em muitos casos a exceção é que se torna a regra, em face de uma realidade na qual pouco se controla.

"[Na iniciativa privada] se você chegar atrasado, você vai ser descontado; se você sair mais cedo, vai ser descontado, vai ter penalidade. Aqui 
geralmente isso é regra. Esse não vigiar cria essas coisas. Com o passar do tempo você vê que todo mundo faz a mesma coisa, ninguém chega na hora. Você pensa assim: ah, pra que que eu vou chegar?”(relato).

Um dos motivos para tal ineficiência é que, fisicamente, o patrão (o Estado) não comparece à organização. Tal ponto de vista pode ser questionado sob inúmeros aspectos, que vão desde a nova composição de propriedade das organizações privadas, até o papel do gerente no processo de trabalho.

"No serviço público, não existe o patrão, só o chefe imediato. Tem gente que tem a postura de chefe, sabe cobrar, tem o espírito de liderança, sabe liderar; outros não sabem e não cobram e aquilo vira uma bola de neve. $\mathrm{O}$ funcionário vai-se viciando naquele comportamento de não ser cobrado” (relato).

Embora critiquem a sua ausência, comparando o trabalho no serviço público com o da organização privada, relativiza-se a importância do controle no que se refere aos principais problemas organizacionais, embora não sejam apresentadas outras alternativas para solucionar tal impasse.

"Há coisas mais sérias do que manter o controle sobre os subordinados.

Você tem que ter um controle sobre os seus subordinados, mas tem outros problemas mais sérios do que isso" (relato).

Com relação ao desempenho na execução do trabalho, o que se discutiu é se o cumprimento de normas, fator altamente valorizado na concepção burocrática, deve ser o principal fator a ser levado em consideração na avaliação do desempenho dos funcionários públicos. As respostas se assemelharam na percepção de que nem sempre o cumprimento de normas equivale a bom desempenho:

“O desempenho é importantíssimo, porque você vê muito funcionário que cumpre [as normas internas], e não tem bom desempenho, porque cumprir as normas é importante, mas não o essencial. $\mathrm{O}$ fato de seguir normas não quer dizer que você seja melhor" (relato).

A remuneração também foi objeto de discussão, em face do seu relacionamento com a questão do desempenho e com o controle organizacional. Afinal, se não é possível medir de forma adequada o desempenho organizacional, como pôr fim à isonomia salarial? Ao mesmo tempo, outra questão que se coloca é o tipo de trabalho desempenhado. De acordo com alguns entrevistados, não é apenas uma questão de associação de maiores salários às maiores cargas de trabalho. Há níveis hierárquicos que merecem ser levados em consideração nessa discussão. Eis algumas opiniões. 
"Quem trabalha mais deve ganhar mais. Tem gente aqui que trabalha muito. $\mathrm{O}$ problema é que as coisas são muito relativas: às vezes a pessoa trabalha muito, mas ela não é eficiente. Você medir trabalho cada dia se torna mais difícil, pois não tem jeito de saber quem trabalha mais e quem trabalha menos. Aqui se você trabalhar menos, trabalhar médio ou trabalhar mais, você recebe o mesmo. Discordo que isso deveria existir” (relato).

Os pontos tratados nas entrevistas, longe de esgotar o assunto em tela, apenas tocam superficialmente no complexo caráter que possui a cultura organizacional, em particular em um ambiente regido por normas burocráticas. Assim como representam modos de encarar a situação atual, as opiniões dos entrevistados dão margem a considerações a respeito das formas de manifestação e percepção dos fenômenos organizacionais para seus diversos componentes. Embora não tenham sido especificamente tratadas as figuras do imaginário local, tampouco foram tais aspectos negligenciados, sendo reconhecida a sua importância no cotidiano organizacional; contudo levando-se em consideração a complexidade intrínseca do constructo, é sem dúvida mais instigante analisá-lo a partir das percepções dos membros da organização sobre aspectos diretamente relacionados ao seu dia-a-dia, como maneira de apreender e inferir a respeito dos efetivos embates travados no exercício de suas funções.

\section{Considerações Finais}

Partindo da premissa de que há uma cultura organizacional peculiar aos ambientes regidos por uma lógica burocrática de organização, o cerne deste estudo é tecer considerações sobre como os padrões objetivos e subjetivos predominantes em unidades administrativas de uma universidade pública se relacionam com a questão da satisfação do cidadão - consumidor por excelência dos serviços públicos. Como são fruto de uma visão específica, as conclusões deste estudo pedem cautela no tocante à generalização, uma vez que restringem a sua aplicabilidade a um contexto particular.

Os dados apresentados dão margem a inferências diversas a respeito de como a própria maneira pela qual a burocracia pública dispõe e aloca seus recursos influencia tanto seu desempenho quanto a sua peculiar cultura. Por um lado, observam-se funcionários conscientes do que se espera deles, enquanto membros da máquina pública, comprometidos com a qualidade na prestação de serviços à população. Por outro, percebe-se uma mão-de-obra politizada e em geral desmotivada com as sucessivas ações do governo no sentido de desestruturar a ima- 
gem do servidor público não apenas em termos institucionais, mas principalmente no que se refere à base de sustentação sindical, política e econômica - esta última mediante congelamento de salários e estímulos ao desligamento em massa.

Em linhas gerais, o relacionamento entre funcionário e organização é de natureza complexa; sob um prisma a realidade atual não representa o que os funcionários gostariam que ela fosse; sob outro aspecto, há um temor generalizado do novo, diverso do estabelecido nos manuais. A noção de burocracia é tão enraizada, que remete à idéia de imobilidade, uma vez que formas alternativas de organização são rejeitadas - ou aceitas até a fase de implementação de mudanças - tal a força dos preceitos reguladores vigentes.

As organizações públicas precisam ter seus fenômenos observados - mesmo a cultura organizacional - com atenção específica, que leve em consideração o ambiente e as demandas peculiares do setor. Nesse sentido, os resultados mais significativos referem-se à natureza contraditória da organização pública. É inegável a existência da burocracia como fator de racionalidade predominante na organização analisada, o que acarreta toda uma série de atitudes voltadas à perpetuação dos processos existentes, condizente com a lógica de sistema fechado que os rege. Os funcionários públicos percebem a necessidade de modificação da maneira pela qual as atividades vêm sendo desempenhadas, maior aproximação com o mercado - entendido aqui como as demandas dos cidadãos - e maior agilidade na resposta às mudanças ambientais; ainda assim, manifestam-se predominantemente de forma negativa, quando a inovação é tratada, deixando claro que mudar é preciso, mas não de forma radical.

A lógica burocrática do serviço público erigiu barreiras para a satisfação do cidadão difíceis de serem superadas, especialmente porque suas bases estão solidamente assentadas sobre a ignorância dos funcionários a respeito do seu próprio potencial de desenvolvimento e sobre o receio de trabalhar em um contexto flexível e sem a presença do manual, que tudo prevê, tudo provê e tudo regula.

Em que pesem as limitações atuais com que se depara a administração pública, uma observação mais acurada da cultura organizacional de um ambiente burocrático permite tanto que se avalie o peso das instituições normativas no que se refere à configuração de valores e pressupostos internos, quanto que se trabalhe com um quadro mais abrangente de análise do que ocorre hoje na esfera pública. Ainda que preliminar, tal iniciativa é promissora, à medida que permitiu delinear como se dão as relações no seu interior, e identificar como a percepção dos seus próprios componentes revela particularidades da concepção e operacionalização da cultura em uma organização burocrática: uma teia complexa de normas, valores, mitos e crenças entre a potencialidade e a realidade. 
NotA

${ }^{1} \mathrm{O}$ autor agradece à Coordenação de Aperfeiçoamento de Pessoal de Nível Superior (CAPES) o apoio recebido.

\section{ReferênCIAS Biblográficas}

AKTOUF, O.

O simbolismo e a cultura de empresa: dos abusos conceituais às lições empíricas. In: CHANLAT, J.-F. (Org.). O indivíduo na organização: dimensões esquecidas. São Paulo: Atlas, 1993. v.1.

BARBOSA, L. N. H.

Cultura administrativa: uma nova perspectiva das relações entre antropologia e administração. Revista de Administração de Empresas, v. 36, n. 4, p. 6-19, out./dez. 1996.

BRESSER PEREIRA, L. C.

Da administração pública burocrática à gerencial. Revista do Serviço Público, v. 120, n. 1, p. 7-41, jan./abr. 1996.

Estratégia e estrutura para um novo estado. Revista do Serviço Público, v. 124, n. 1, p. 5-25, jan./abr. 1997.

CANNIE, J. K.

Mantendo clientes fiéis e para sempre. São Paulo: Makron Books, 1994.
CARBONE, C.

A universidade e a gestão da mudança organizacional a partir da análise sobre o conteúdo dos padrões interativos. Revista de Administração Pública, v. 29, n. 1, p. 34-47, jan./mar. 1995.

CASTOR, B. V. J. et al.

Estado e administração pública: reflexões. Brasília: FUNCEP, 1987.

FLEURY, M. T. L.

Cultura organizacional - os modismos, as pesquisas, as intervenções - uma discussão metodológica. In: ENCONTRO ANUAL DA ANPAD, XII, 1988, Natal. Anais... Natal: ANPAD, 1988.

O desvendar a cultura de uma organização - uma discussão metodológica. In: FLEURY, M. T. L.; FISCHER, R. M. Cultura e poder nas organizações. São Paulo: Atlas, 1990. 
FREEMANTLE, D.

Incrível atendimento ao cliente.

São Paulo: Makron Books, 1994.

FREITAS, A. B.

Traços brasileiros para uma análise organizacional. In: PRESTES MOTTA, F. C.; CALDAS, M. P. (Org.). Cultura brasileira e cultura organizacional. São Paulo: Atlas, 1997.

FREITAS, M. E.

Cultura organizacional: formação, tipologias e impacto. São Paulo: Makron Books, 1991.

GRACIOSO, F.

A excelência em marketing nos anos noventa. São Paulo: Atlas, 1995.

HICKSON, D. J.;

PUGH, D. S.

Management worldwide: the impact of societal culture on organizations around the world. Harmonthsworth: Penguin, 1995.

HOFSTEDE, G.

Cultures and organizations: software of the mind. New York: McGraw-Hill, 1991.

KLIKSBERG, B.

Como transformar o estado para além de mitos e dogmas. Brasília: ENAP, 1992.

Redesenho do estado para o desenvolvimento sócio-econômico e a mudança: uma agenda estratégica para a discussão. Revista de Administração Pública, v. 28, n. 3, p. 5-25, jul./set. 1994.

MEDICI, A. C.; SILVA, P. L. B.

A administração flexível: uma introdução às novas filosofias de gestão. Revista de Administração Pública, v. 27, n. 3, p. 26-36, jul./set. 1993.

MERTON, R. K.

Estrutura burocrática e personalidade. In: CAMPOS, E. C. (Org.). Sociologia da burocracia. Rio de Janeiro: Zahar, 1966.

O'REILLY, C.

Corporations, culture and commitment: motivation and social control in organizations. California Management Review, p. 9-25, Summer 1989.

RODRIGUES, S. B.

$O$ chefinho, o telefone e o bode: autoritarismo e mudança cultural no setor de telecomunicações. Belo Horizonte, 1991. Tese (Livre Docência) - Centro de PósGraduação e Pesquisa em Administração, Universidade Federal de Minas Gerais.

RODRIGUES, S. B.;

COLLINSON, D. L.

'Having fun'? Humour as resistance in Brazil. Organization Studies, v. 16, n. 5, p. 739-768, 1995. 
SANTOS, A. M.

Cultura organizacional e motivação para o poder: um estudo comparativo entre o setor bancário oficial e privado de Belo Horizonte. Belo Horizonte, 1990. Dissertação (Mestrado em Administração) - Centro de Pós-Graduação e Pesquisa em Administração, Universidade Federal de Minas Gerais.

SANTOS, N. M. B. F.

Diagnosticando a cultura organizacional através da abordagem tipológica de Quinn: uma pesquisa nas empresas brasileiras do setor têxtil. In: ENCONTRO ANUAL DA ANPAD, XVIII, 1994, Curitiba. Anais... Curitiba: ANPAD, 1994.
SILVA, C. E. S.

Autonomia de gestão e concorrência: em busca de novas formas de gestão do setor público em um contexto pós-fordista. Revista de Administração Pública, v. 28, n. 3, p. 211-228, out./dez. 1994.

STAKE, R. E.

Case studies. In: DENZIN, N. K.; LINCOLN, Y. S. (Org.). Handbook of qualitative research. London: Sage Publications, 1994. 